\title{
A study of early neonatal morbidity profile in a district teaching hospital, Mysore, India
}

\section{Vadiraja Nagarajarao, Mansoor Ahmed, Anagha Ravi ${ }^{\prime}$, Gayathri Holenarasipur Pattabhirama', Krishnamurthy Balasundaram $^{2}$}

Department of Community Medicine and ${ }^{2}$ Pediatrics, Mysore Medical College and Research Institute, Mysore, ${ }^{1}$ Post Graduate

Student, Yuvaraja College,

Mysore, Karnataka, India

Address for the Correspondence: Dr. N. Vadiraja,

Department of Community Medicine, Mysore Medical College and Research Institute, Mysore, India.

E-mail:Vadi18@rediffmail.com

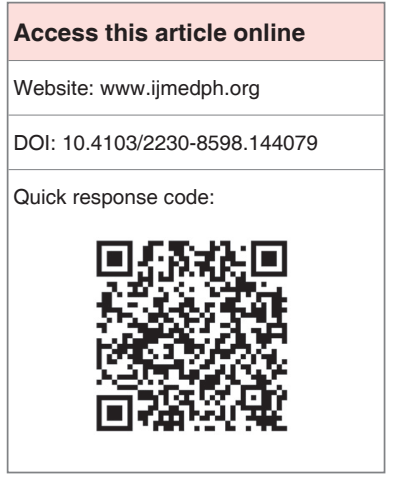

Introduction: Early neonates are more prone towards infections and deaths. As a result we are interested in finding out the health behavior of inborn early neonates in a district hospital of Mysore. Materials and Methods: A total of 24,578 live births were monitored for their morbidity status from September 2011 to June 2013. The number of morbidity causes was detected for every 100 early neonates, monthly wise. The non-conformities behavior was observed through Poisson u-chart with variable control limits. $20 \%$ vital few contributors that contributes to variations in morbidity and mortality aspects of early neonates were detected through checklists and super imposed Pareto charts. Results: The number of causes per inspection unit for sample number 9 is out of control. Values corresponding to samples 1 and 2 are within the warning region. It appears that hypoxic ischemic encephalopathy (HIE)/moderate-severe birth asphyxia is the major contributing factor for both morbidity and mortality based on the occurrences. However, in the process of detecting the impact of morbidity factor on their corresponding mortality, it is found that the major nonconformity factor is major congenital malformation (MCM) and not HIE/Moderate-severe birth asphyxia as MCM has 0.217 chance of causing mortality, whereas HIE has 0.19 chance standing at the fourth position. Conclusion: We conclude that the hospital management needs to develop appropriate preventive and management strategies for the major causes viz., MCM, sepsis/pneumonia/meningitis and respiratory distress syndrome.

Key words: Check sheet, early neonatal morbidity, early neonatal mortality, pareto chart, poisson random variable

\section{INTRODUCTION}

The worlds' poorest populations live in the shadow of a group of old enemies - Malnutrition, childhood infections, poor maternal and perinatal health and high fertility. Every year about 7.5 million children die primarily due to poor maternal and child health care. Approximately $65 \%$ of all child deaths are from three causes - Acute respiratory infections, diarrhea and immunization preventable diseases. ${ }^{[1]}$ The fact is that childhood morbidity is less routinely measured. Birth defect registries, neonatal intensive care use, discharge diagnoses and neonatal health surveys provide some estimates of morbidity. ${ }^{[2]}$ In the new millennium, more efforts need to be done to develop sustainable approaches to improve child health to reduce both morbidity and mortality, if we are to ensure that children not only survive but also grow in a healthy environment with access to basic essential health services. Early neonates are more prone towards infections and deaths. ${ }^{[3]}$ Hence, we planned to undertake a study in the government teaching hospital, Mysore, which is situated in a densely populated area with heavy motor traffic in the center of the city. As a result, we are interested in finding out the health behavior of inborn early neonates.

\section{Objectives}

1. To show that the morbidity profile of early neonates in the hospital is statistically under control.

2. Grading the seriousness of morbidity and mortality factors.

3. To show that the most important morbidity factor is statistically under control.

4. To study the impact of morbidity factors on mortality aspect. 


\section{MATERIAL AND METHODS}

A total of 24,578 live births were monitored for their morbidity status from September 2011 to June 2013. The number of morbidity causes was detected for every hundred early neonates monthly wise. Sample 1 being September 2011, Sample 2 being October 2011 and so on. A group of hundred early neonates is the inspection unit. Each morbidity cause is considered as a defect or nonconformity in an early neonate. As a result, the total number of nonconformities in a sample of inspection units follows a Poisson random variable. ${ }^{[4,5]}$ The nonconformities behavior is observed through Poisson u-chart with variable control limits. $20 \%$ vital few contributors to variations in morbidity and mortality aspects of early neonates were detected through checklists and super imposed Pareto charts.

\section{RESULTS}

The u-chart 2 and 3 sigma control limits are given in Table 1. Warning zone is the area between upper control limits of 3 and 2 sigma. The process mean is denoted by $\mathrm{U}$ bar (11.307) indicating the average number of causes per inspection unit. The number of causes per inspection unit for sample number 9 is out of control. Values corresponding to samples 1 and 2 are within the warning zone. The information is more clearly visualized in Figure 1 . It is observed from Table 2 that HIE/moderate-severe birth asphyxia $(33 \%)$ is the major contributor to the morbidity profile, followed by sepsis/pneumonia/meningitis (15.6\%) respiratory distress syndrome
$(13.4 \%)$ and jaundice-requiring phototherapy (12.6\%). These four contribute $74.4 \%$ [Figure 2] in total to the number of causes in early neonates. It is also noted that HIE/moderate-severe birth asphyxia is the major contributor $(30.8 \%)$, followed by prematurity $(23.7 \%)$ and sepsis/pneumonia/meningitis (15.9\%) to the mortality profile [Table 3]. These three contribute $70.5 \%$ in total to the early neonatal mortality. From Figure 3 the frequencies of occurrences of HIE/moderate-severe birth asphyxia (178), prematurity (137) and sepsis/pneumonia/meningitis (92) are noted. However, Table 4 indicates that in general, each morbidity factor has 0.158 chance of contributing to the death. With 0.217 probability the MCM is leading

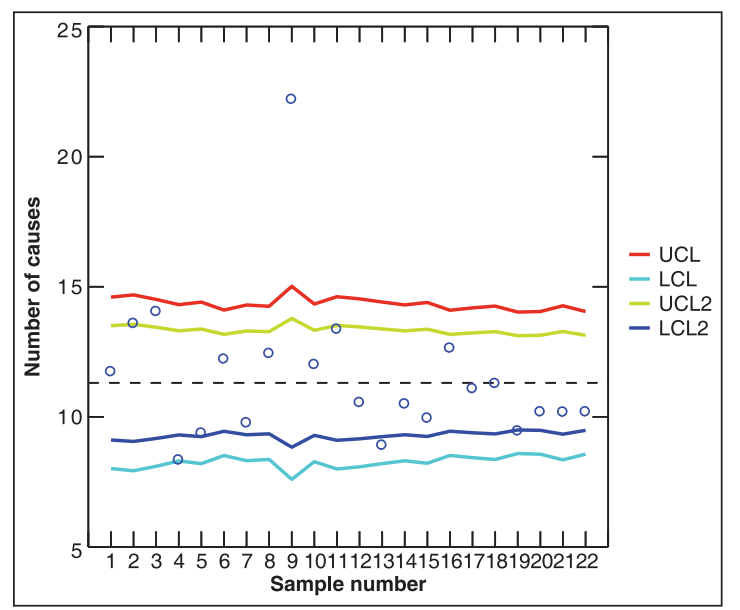

Figure 1: U-chart showing control limits

\begin{tabular}{|c|c|c|c|c|c|c|c|c|}
\hline $\begin{array}{l}\text { Sample } \\
\text { number }\end{array}$ & $\begin{array}{c}\text { Sample size } \\
\text { (No. of live births) }\end{array}$ & $\begin{array}{c}\text { No. of morbidity } \\
\text { causes }\end{array}$ & $\begin{array}{c}\text { No. of } \\
\text { inspection units }\end{array}$ & $\begin{array}{l}\text { No. of causes per } \\
\text { inspection unit }\end{array}$ & UCL & LCL & UCL2 & LCL2 \\
\hline 1 & 938 & 110 & 9.38 & 11.72707889 & 14.60061 & 8.013108 & 9.111026 & 9.111026 \\
\hline 2 & 891 & 121 & 8.91 & 13.58024691 & 14.68637 & 7.927353 & 9.053855 & 9.053855 \\
\hline 3 & 990 & 139 & 9.9 & 14.04040404 & 14.51294 & 8.100778 & 9.169472 & 9.169472 \\
\hline 4 & 1128 & 94 & 11.28 & 8.333333333 & 14.31043 & 8.30329 & 9.30448 & 9.30448 \\
\hline 5 & 1057 & 99 & 10.57 & 9.366130558 & 14.40967 & 8.204053 & 9.238322 & 9.238322 \\
\hline 6 & 1302 & 159 & 13.02 & 12.21198157 & 14.10254 & 8.511184 & 9.443076 & 9.443076 \\
\hline 7 & 1137 & 111 & 11.37 & 9.762532982 & 14.29852 & 8.315201 & 9.312421 & 9.312421 \\
\hline 8 & 1175 & 146 & 11.75 & 12.42553191 & 14.24975 & 8.363975 & 9.344937 & 9.344937 \\
\hline 9 & 739 & 164 & 7.39 & $22.19215156^{*}$ & 15.01768 & 7.596039 & 8.832979 & 8.832979 \\
\hline 10 & 1108 & 133 & 11.08 & 12.00361011 & 14.33742 & 8.276304 & 9.286489 & 9.286489 \\
\hline 11 & 928 & 124 & 9.28 & 13.36206897 & 14.61831 & 7.995409 & 9.099226 & 9.099226 \\
\hline 12 & 977 & 103 & 9.77 & 10.54247697 & 14.5342 & 8.079518 & 9.155299 & 9.155299 \\
\hline 13 & 1056 & 94 & 10.56 & 8.901515152 & 14.41114 & 8.202584 & 9.237343 & 9.237343 \\
\hline 14 & 1135 & 119 & 11.35 & 10.4845815 & 14.30115 & 8.312567 & 9.310664 & 9.310664 \\
\hline 15 & 1066 & 106 & 10.66 & 9.943714822 & 14.39654 & 8.217179 & 9.247073 & 9.247073 \\
\hline 16 & 1306 & 165 & 13.06 & 12.63399694 & 14.09825 & 8.515469 & 9.445933 & 9.445933 \\
\hline 17 & 1228 & 136 & 12.28 & 11.07491857 & 14.18554 & 8.428182 & 9.387741 & 9.387741 \\
\hline 18 & 1171 & 132 & 11.71 & 11.27241674 & 14.25477 & 8.358953 & 9.341589 & 9.341589 \\
\hline 19 & 1376 & 130 & 13.76 & 9.447674419 & 14.02632 & 8.587398 & 9.493885 & 9.493885 \\
\hline 20 & 1355 & 138 & 13.55 & 10.18450185 & 14.04731 & 8.566405 & 9.47989 & 9.47989 \\
\hline 21 & 1160 & 118 & 11.6 & 10.17241379 & 14.26871 & 8.345009 & 9.332292 & 9.332292 \\
\hline 22 & 1355 & 138 & 13.55 & 10.18450185 & 14.04731 & 8.566405 & 9.47989 & 9.47989 \\
\hline
\end{tabular}




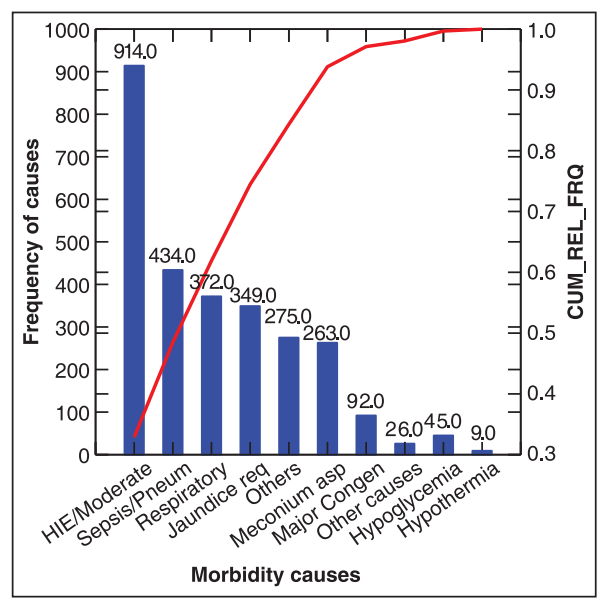

Figure 2: Pareto chart showing order of seriousness

\begin{tabular}{|c|c|c|c|}
\hline Morbidity Causes & Frequency & $\begin{array}{c}\text { Relative } \\
\text { Frequency }\end{array}$ & $\begin{array}{l}\text { Cumulative } \\
\text { Relative } \\
\text { Frequency }\end{array}$ \\
\hline $\begin{array}{l}\text { *HIE/Moderate- } \\
\text { Severe Birth } \\
\text { Asphyxia }\end{array}$ & 914 & 0.328895 & 0.328895 \\
\hline $\begin{array}{l}\text { Sepsis/Pneumonia/ } \\
\text { Meningitis }\end{array}$ & 434 & 0.156171 & 0.485066 \\
\hline $\begin{array}{l}\text { Respiratory Distress } \\
\text { syndrome }\end{array}$ & 372 & 0.133861 & 0.618927 \\
\hline $\begin{array}{l}\text { Jaundice requiring } \\
\text { phototherapy }\end{array}$ & 349 & 0.125585 & 0.744512 \\
\hline Others & 275 & 0.098956 & 0.843469 \\
\hline $\begin{array}{l}\text { Meconium aspiration } \\
\text { syndrome }\end{array}$ & 263 & 0.094638 & 0.938107 \\
\hline $\begin{array}{l}\text { Major Congenital } \\
\text { Malformation }\end{array}$ & 92 & 0.033105 & 0.971212 \\
\hline $\begin{array}{l}\text { Other causes of } \\
\text { respiratory distress }\end{array}$ & 26 & 0.009356 & 0.980568 \\
\hline Hypoglycemia & 45 & 0.016193 & 0.996761 \\
\hline Hypothermia & 9 & 0.003239 & 1 \\
\hline Total & 2779 & & \\
\hline
\end{tabular}

*HIE = Hypoxic ischemic encephalopathy

the list, and hence it is the major morbidity factor and is followed by sepsis/pneumonia/meningitis with 0.212 chance. Mortality figures are corresponding to the major morbidity cause. Figure 4 depicts the u-chart for MCM. It is observed that it is statistically under control. Process mean is indicated through the dotted-line and is 0.03455.

\section{DISCUSSION}

Any hospital situated in the midst of the city will have lot of environmental impacts on the newborns. The Government teaching hospital in Mysore is located in the heart of the city and has its own peculiar set of environmental conditions. As a result, newborn is more prone towards higher morbidity and mortality.

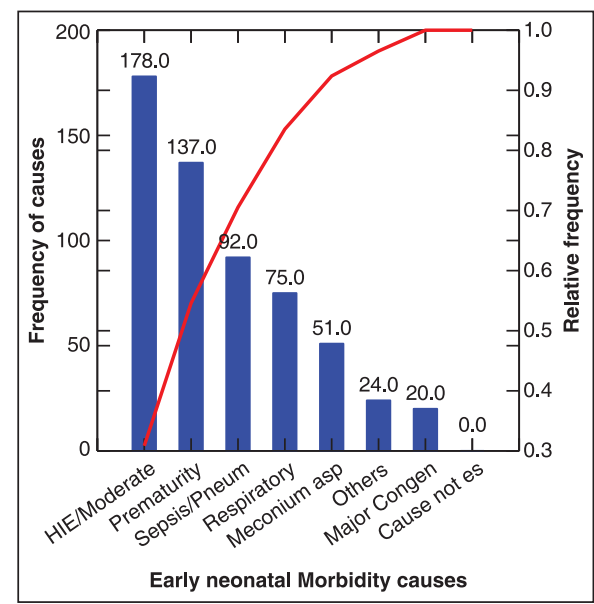

Figure 3: Pareto chart superimposed by cumulative frequency line chart for mortality causes

\begin{tabular}{|c|c|c|c|}
\hline Cause of Death & Frequency & $\begin{array}{l}\text { Relative } \\
\text { Frequency }\end{array}$ & $\begin{array}{l}\text { Cumulative } \\
\text { Relative } \\
\text { Frequency }\end{array}$ \\
\hline $\begin{array}{l}\text { HIE/Moderate-Severe } \\
\text { Birth Asphyxia }\end{array}$ & 178 & 0.3084922 & 0.30849 \\
\hline Prematurity & 137 & 0.23743501 & 0.545925 \\
\hline $\begin{array}{l}\text { Sepsis/Pneumonia/ } \\
\text { Meningitis }\end{array}$ & 92 & 0.15944541 & 0.70537 \\
\hline Respiratory & 75 & 0.12998267 & 0.835353 \\
\hline $\begin{array}{l}\text { Meconium aspiration } \\
\text { syndrome }\end{array}$ & 51 & 0.08838821 & 0.923741 \\
\hline Others & 24 & 0.04159445 & 0.965336 \\
\hline $\begin{array}{l}\text { Major Congenital } \\
\text { Malformation }\end{array}$ & 20 & 0.03466205 & 1 \\
\hline Cause not established & 0 & 0 & 1 \\
\hline Total & 577 & & \\
\hline
\end{tabular}

In this context, we are interested to understand the health patterns and its impact on mortality. Health patterns are measured through the causes and each cause is termed as defect or nonconformity as it does not meet with the standard specifications. The information on the number of nonconformities collected monthly wise per inspection unit follows Poisson random variable and is interpreted using the Poisson u-chart with variable control limits to detect if the number of defects is under 3 sigma control indicating the impact of just common cause variation rather than the special cause variation. To achieve this, specific control limits $(3$ and 2 sigma) have been detected for "Number of causes per inspection unit" and are given in Table 1 . The process mean is coming out to be 11.307 defects per inspection unit. Values corresponding to the different samples are dense towards the center line without following any specific pattern in figure 1 and well within the control limits indicating the fact that the number of defects is statistically under control. However, it is clear that the value for sample number 9 corresponding to May 2012 is going out of control indicating the impact some special cause. Sample numbers 2 and 3 are in the 


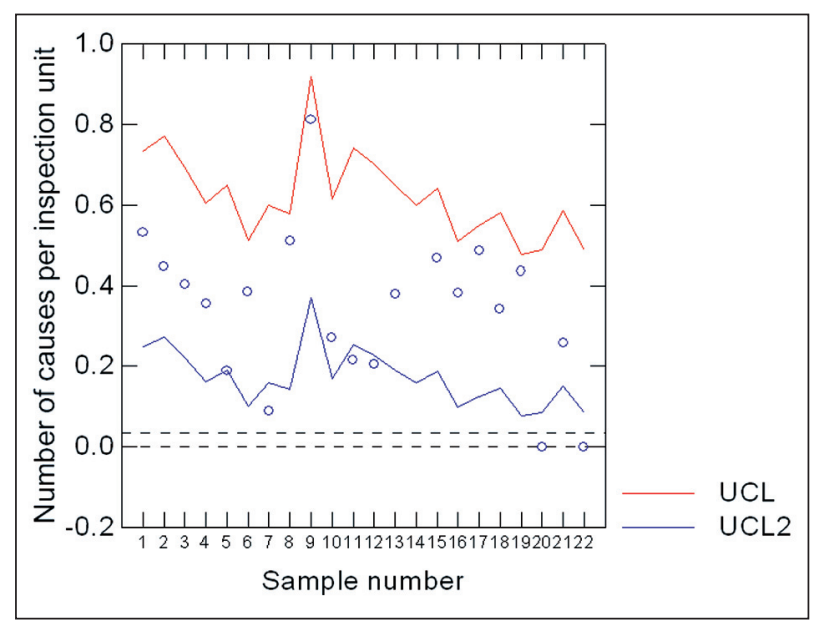

Figure 4: U-chart for major congenital malformation morbidity cause

\begin{tabular}{lccc} 
Table 4: Impact of morbidity on mortality \\
\hline Causes & $\begin{array}{l}\text { Frequency } \\
\text { (morbidity) }\end{array}$ & $\begin{array}{c}\text { Frequency } \\
\text { (mortality) }\end{array}$ & $\begin{array}{c}\text { Chance of } \\
\text { contribution to } \\
\text { death }\end{array}$ \\
\hline $\begin{array}{l}\text { HIE/Moderate- } \\
\text { Severe Birth }\end{array}$ & 914 & 178 & 0.194748 \\
$\begin{array}{l}\text { Asphyxia } \\
\text { Sepsis/Pneumonia/ }\end{array}$ & 434 & 92 & 0.211982 \\
$\begin{array}{l}\text { Meningitis } \\
\begin{array}{l}\text { Respiratory } \\
\text { Distress syndrome }\end{array}\end{array}$ & 372 & 75 & 0.201613 \\
$\begin{array}{l}\text { Others } \\
\text { Jaundice requiring } \\
\text { phototherapy }\end{array}$ & 349 & 24 & 0.068768 \\
$\begin{array}{l}\text { Meconium } \\
\text { aspiration } \\
\text { syndrome }\end{array}$ & 263 & 0 & 0 \\
$\begin{array}{l}\text { Major Congenital } \\
\text { Malformation }\end{array}$ & 92 & 51 & 0.193916 \\
$\begin{array}{l}\text { Other causes of } \\
\text { respiratory distress } \\
\text { Hypoglycemia }\end{array}$ & 26 & 0 & 0.217391 \\
Hypothermia & 45 & 0 & 0 \\
Total & 9 & 0 & 0 \\
\hline
\end{tabular}

danger zone; danger zone being the area between upper control limits of 2 and 3 sigma.

Since we are looking into the disease contribution to the morbidity and mortality profile, it is meaningful to detect the $20 \%$ vital few creating $80 \%$ of the problems using Pareto chart concept, which is achieved through the check sheet approach. ${ }^{[6,7]}$ Check sheet is the table containing the information on the major causes based on their occurrences with relative and cumulative relative frequencies. Tables 2 and 3 are representing the check sheets for morbidity and mortality, respectively. Pareto chart super imposed by cumulative relative frequency line chart for morbidity causes in Figure 2, indicates the order of seriousness based on their occurrences. We found that $74 \%$ of morbidity is caused by the HIE/moderate-severe birth asphyxia, sepsis/pneumonia/ meningitis and respiratory distress syndrome. On similar lines, from Figure 3, we detected that $70.5 \%$ of the mortality is caused by HIE/moderate-severe birth asphyxia, pre-maturity and sepsis/ pneumonia/meningitis. It appears that HIE/moderate-severe birth asphyxia is the major contributing factor for both morbidity and mortality based on the occurrences.

However, in the process of detecting the impact of morbidity factor on their corresponding mortality, it is found that the major nonconformity factor is MCM and not HIE/moderate-severe birth asphyxia as MCM has 0.217 chance of causing mortality whereas HIE has 0.19 chance standing at the fourth position. This promotes the idea for detecting whether MCM is statistically under control. From Figure 4, it is clear that MCM is well under the control limits though most of MCM points for various months are in upper danger level calling for preventive and managing techniques by the hospital.

\section{CONCLUSION}

This study is a unique and novel approach in understating the pattern of defects/morbidity factors in early neonates. We conclude that the hospital management needs to develop the preventive and managing strategies for the major causes viz MCM, sepsis/pneumonia/ meningitis and respiratory distress syndrome. This study speaks about the detecting methodology of the major causes.

\section{REFERENCES}

1. Wallace R. In: Maxcy-Rosenau-Last. Text book of Public Health and Preventive Medicine. Mc Graw Hill: $15^{\text {th }}$ ed. 1294.

2. Oxford Textbook of Public Health. In: Detels R, Beaglehole R, Lansang A, Gulliford M, editors. Oxford press: $4^{\text {th }}$ ed. p. 1604-7.

3. Park K. Preventive and Social Medicine. M/s Banarsidas Bhanot publishers: $21^{\text {st }}$ ed. p. 521.

4. Montgomery DC. Introduction to Statistical Quality Control. New York: John Wiley \& Sons: $3^{\text {rd }}$ ed. 1996. p. 314.

5. Ishikawa K. Guide to Quality Control. Tokyo, Japan: Asian Productivity Organization; 1982. p. 225.

6. Shewhart WA. Economic Control of Quality of Manufactured Product. Van Nostrand; 1931.

7. Montgomery DC, Woodall HM. A discussion of statistically-based process monitoring and control. J Qual Technol 1997;29:121-62.

How to cite this article: Nagarajarao $V$, Ahmed M, Ravi $A$, Pattabhirama GH, Balasundaram K. A study of early neonatal morbidity profile in a district teaching hospital, Mysore, India. Int J Med Public Health 2014;4:396-9.

Source of Support: Nil, Conflict of Interest: None declared. 